THE "UNILENS." A NOVEL FORM OF TELESCOPE.

A novel form of telescope or field glass, to which the name "unilens" has been applied, has recently been devised by Major Baden-Powell, F.R.A.S., of London, the feature of which is that it can be carried is the waistcoat pocket. As may be gathered from its title, the instrument comprises a single lens of convex form, $2 \frac{1}{2}$ inches in diameter and mounted in a simple metal rim. The mount is provided with a small clip and screw, by means of which the lens can be readily attached to a walking stick or umbrella, being carried, as the illustration shows, at the outer end. With this simple device it is possible to obtain an enlarged view of distant objects, the maximum magnification being about four diameters. In view of the simple nature of the device and its handy form, it constitutes a convenient and efficient means for all ordinary purposes where a slight magnification is desired, being capable of fulfilling the same functions as the general type of opera and field glasses; but owing to its flat form and small limensions, it can be car. ried in the pocket without inconvenience.

When mounted on a walking stick and held at the full extended length of the arm, its greatest efficiency is obtained, since the farther it is held from the eye, the greater is the magnification. At the full extended length, which is equivalent to a distance of about six feet between the eye and the lens, the object has its maximum magnification, though at this point a slight maximum magnification, though at this point a slight
blurring is discernible. The most convenient and easy position to assume when studying subjects through the device is a sitting posture with the hand holding the stick resting on the knee, at which point the glass, about four feet distant from the eye, enables the user to view objects clearly and sharply. The lens, however, is always in focus, and consequently is a handy form of hand-glass, especially when held at arm's length. It then forms a great aid to the natural sight more particularly in the examination of hanging pictures, the architectural features of a building, and so forth, and it will even fulfill the purposes of an opera glass at the theater.

From an astronomical point of view the "unilens" has no great claim, though in this work it has its possibilities. For instance, in looking at the Pleiades through the "unilens," eight stars can be discerned quite easily, whereas with the naked eye only six can generally be distinguished. In following the movements of birds and animals in their natural habitat from a distance of a few yards, the glass is of great utility to the naturalist.

Although the "unilens" is not applicable to all sights, yet, according to one very widely known firm of London opticians it may be safely said that three persons out of four can use it quite well. To be sure, those afficted with myopia or short sight cannot see very clearly through the single lens, but when it is employed in conjunction with a concave eyeglass, not only can they see clearly through the "unilens," but such sights are found to be improved under ordinary circumstances by the habitual use of the eyeglass.

\section{THE NEW LUSOL LAMP.}

$$
\text { BX JACQUES BOYER. }
$$

The introduction of the lusol lamp marks an era in the history of illumination for, according to the calculations of its inventor, the new illuminant furnishes for a cost of one cent an amount of light which would cost 4 or 5 cents if furnished by kerosene, 8 or 10 cents if produced by electricity, and 15 or 20 cents if obtained from animal or vegetable oils.

There is no mystery about the composition of the substance, which is known by the trade name of lusol. It is simply impure benzene obtained by distilling coal tar. zene obtained by distilling coal tar
It is not a definite chemical com pound but a mixture of hydro carbons containing a very high percentage of carbon. The various forms of apparatus which have been devised by M. Louis Denayrouze for the utilization of lusol in rouze for the utilization of lusol in
domestic and other illumination domestic and other illumination
are not simple lamps but rather complicated devices for the safe production and combustion of lusol vapor.

If we dissect a lusol lamp of the small, or household, type we find that the openings of the lusol reservoir are hermetically closed by conical screw plugs, in order to prevent escape of the thin and very inflammable fluid if the lamp is overturned, or by capillary action or "sweating," in the normal posi-

tion. On removing the burner we see a central tube extending nearly to the bottom of the reservoir and surrounding a metal core, the space between which and the tube is very tightly filled by a tubular cotton wick. The tube, however, is closed at the top so that the wick does not protrude from the reservoir or come into direct contact with the flame. The sole function of the wick is to raise the liquid lusol, by capillary action, to a small vaporizing chamber just above the top of the wick. From this chamber the vapor escapes through an orifice so small that it cannot be seen in

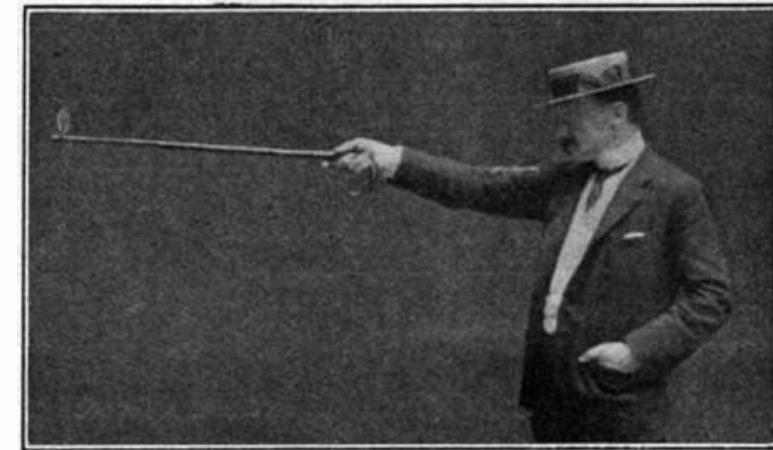

Greatest Magnification at the Maximum Distance from the Eye.

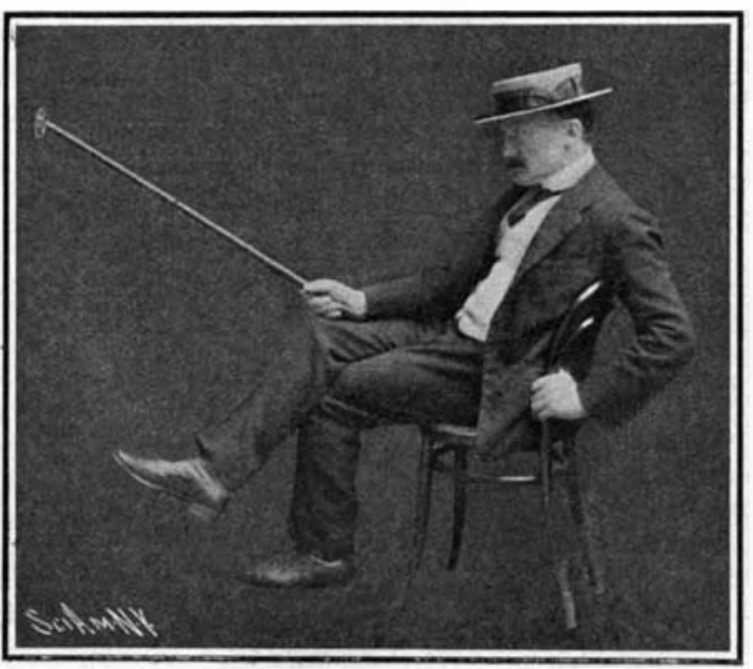

A Convenient Method of Viewing Objects at a Distance.

THE "UNILENS."

the illustration. This hole, fine as a hair, is the only means of comniunication between the interior of the reservoir and the exterior. And as the liquid cannot reach this hole without traversing the tightly com pressed wick there is no danger of leakage in this way. On the other hand, this orifice regulates the flow of the vapor to which it gives a velocity sufficient to cause it to carry with it the proportion of air re-

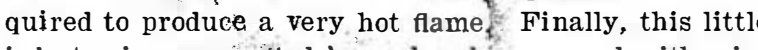
injector is surmounted by a chamber covered with wir gauze in order to perfect the mixture of air and vapor and to prevent the flame from striking back to the servoir.

But in order to produce rapid vaporization heat must be applied, and for this purpose M. Denayrouze has adopted an original device which he had already employed in one of his earlier inventions. As the photo-

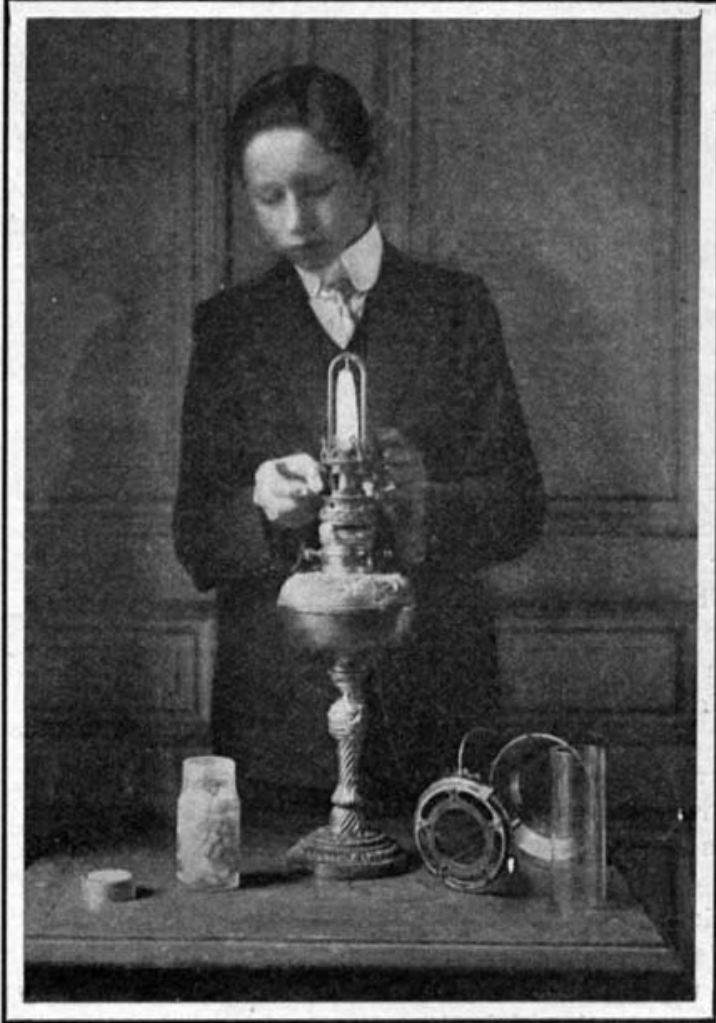

LIGHTING A SMALL LUSOL LAMP WITH ALCOHOL PABTILLES,

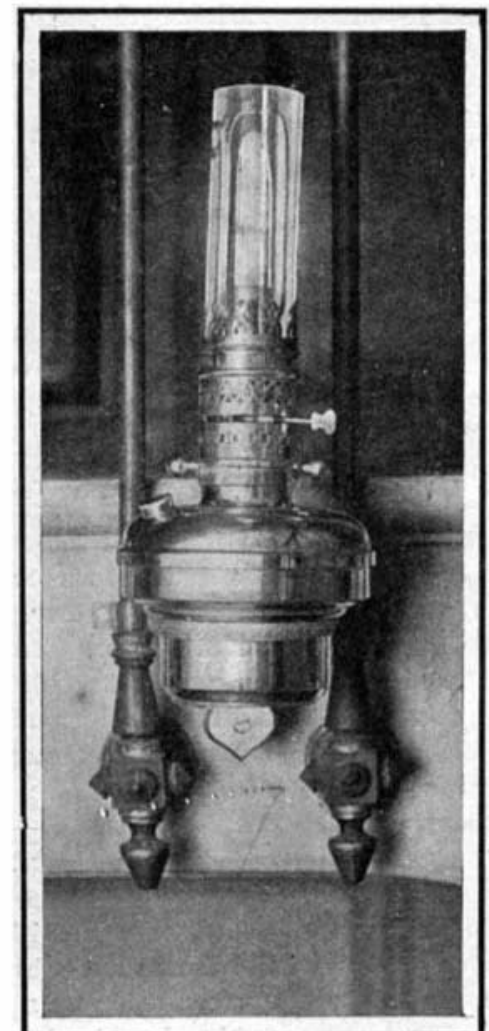

LUBOL LAMP DESIGNED FOR A BTAIRCABE. graph shows, the inverted U-shaped support of the Auer mantle is not a thin wire, as in most incandescent lamps, but is massive and is soldered to the base of the distillation chamber. When the lamp is burning this upport is very hot, and it consequently heats and vaporizes the lusol with which the top of the wick is saturated and which is continuously replaced by fresh liquid raised from the reservoir by capillary action.

But, in order to light the lamp, this support of the mantle must first be heated by an extraneous source. Different methods are employed in lusol lamps of the various types. In lighting a parlor, office, or hall lamp the upper part of the burner is first raised with the left hand. This action exposes two clusters of points on which two alcohol pastilles, consisting of paraffined cotton soaked in alcohol, are next placed. The gallery is then replaced and the pastilles are lighted with a match.

Street lamips of the type now in experimental use n the Square du Ranelagh, in Paris, have little reservoirs which can be filled with alcohol by means of a vessel mounted on a pole. In every case, however, a little time elapses before the mantle glows with maximum brightness.

In the very large street lamps, which rival the electric arc in intensity, the upward flow of liquid to recapillarity alone. It is consequently maintained by low air pressure, involving the employment of only a very small volume of air. The apparatus which produces the air pressure consists of two small vessels connected by a long India-rubber tube. At the beginning of the operation one of these vessels is emptyor rather, filled with air-while the other, placed about 5 feet higher, is filled with glycerine. The glycerine flows slowly down the tube, compressing the air and forcing it into the lusol reservoir, and thus causing the lusol to rise in the wick. The operation is repeated once a day, by simply raising the filled vessel and lowering the other. A three-way cock may be arranged to apply and remove the pressure so that the lamp may be operated with or without pressure as desired. In one form of lamp the lusol and glycerine reservoirs are ingeniously combined, so that there is only one descending tube which, together with the air chamber, is concealed in the chandelier.

In point of economy the lusol lamp appears to surpass all other known lighting apparatus. A Denayrouze lamp having the power of 10 Carcel burners costs 0.3 of a cent per hour, while the same illumination produced by stearine candles costs 36 cents per hour.

The use of lusol, however, is attended with certain inconveniences, the most serious of which is the necessity of filling the lamps and the time consumed in lighting them. On the other hand, it does not appear to be particularly dangerous. M. Lucion, the Belgian engineer who furnished the information on which this article is based, truly observes that: "Electricity is dangerous, causing death and fires due to short circuits. Gas is a frequent cause of asphyxiation, voluntary and involuntary. Acetylene is explosive, and a surgeon of my acquaintance was recentsummoned in one day to attend five women fatally burned in five separate accidents with essential thing is to know how to use all these dangerous things."

Lusol, while it is in the lamp, is perfectly harmless. It cannot escape in the liquid form and the flame cannot strike back to a space filled with vapor, as it can in a kerosene lamp. Furthermore, the lusol reservoir remains cold even after the lamp has been burning for hours, owing to the following arrangement: The central tube is double, the space between the tubes communicating with the external air, and the inner tube, in contact with the wick, being made of an alloy which is a comparatively poor conductor of hent. This air-cooling device has another object, in addition to safety, for if the tube should become hot the lusol would be vaporized so rapirly that its loss could ot be supplied by capillary action. The lamp is extinguished instant. ly by moving a little lever which closes the small orifice for the vapor. The lamp should be filled very carefully, at a distance from all lights and fires and never while the lamp is burning.

A favorable forecast for the future of the lusol. lamp may be drawn from the past record of its inventor. Denayrouze and Jablochkof were the first champions of the electric light in Paris. Later M. Denayrouze became the most ardent advocate of incandescent lighting by means of alcohol and he 
will, doubtless, soon apply to his new invention improvements of detail that will insure its success and extensive employment. The peculiar merit of the luso lamp is the elimination of all mechanism. As we have seen, capillarity and the heat of combustion suffice to raise the liquid, vaporize it, and mix the vapor with the quantity of air that is required to accelerate its combustion and cause the mantle to glow with dazzling brilliancy. Finally, the lusol dight needs no costly and inconvenient system of factories, tanks, and pipes, or wires.

How Rats Disseminate Plague.

That the rodent is an active agent in the propagation of plague has been a steadfastly maintained theory among scientists for many years past, but exactly how an epidemic is disseminated among the rats and also communicated therefrom to human beings it has been left to the special plague commission appointed by the Indian government to determ ine. This scientific commission is still engaged in its undertaking, but the discoveries been made are th such parameady importance, that a short and interim importance, that a short and interim lished. In the course of this proceeding the commissioners definitely state that the disease is conveyed

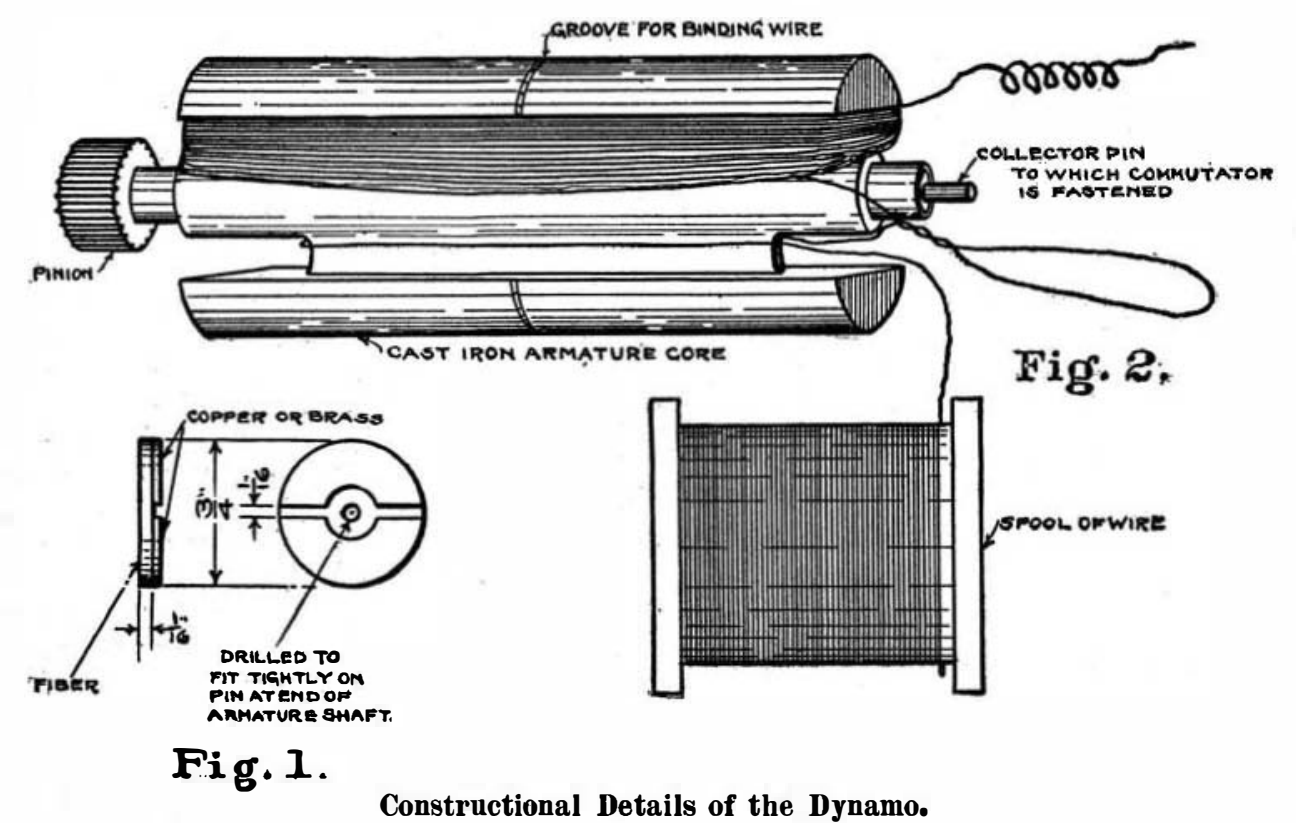

A SIMPLE EXPERIMENTAL DYNAMO. BY PAUL H. WOODRUT energy is a very convenient piece of apparatus for experimental purposes, as it requires little power to drive it yet may be made to take the place of several cells of speed.
A generator giving from 30 to 40 watts of electrical

felt when the handle is turned at a very moderate

Having made our purchase, we proceed to dismantle it. Take out the screws in the brass enci plates or bearings, and remove the armature. The contact spring previously spoken of would best be removed now, as we shall not need it. The armature in most of these machines is $1 \frac{1}{2}$ inches in diameter, of the $\mathrm{H}$ or shuttle form, and wound with No. 31 wire. This should all be unwound with care, as it may come in handy for making other apparatus.

Now, while the armature is bare, we will make a commutator. This consists of a $3 / 4$-inch disk of red fiber, 1-16 inch thick, with a center hole that is a drive fit on the pin in the rear end of the armature shaft. On one side of this disk are fastened the two halves of a $3 / 4$-inch copper or brass washer, which has been sawed or filed into two equal parts. These may be drilled and tapped for small machine screws put through the fiber, or they may be cemented to the disk, exactly as Fig. 1 shows them. But before fixing the commutator on the shaft, we would better rewind the armature. As we have decided on the 8 and 16-volt arrangement, we will use No. 23 wire. Before starting, be sure that the iron is well in

from one rat to another and also to human beings by have our choice of voltage; thus, allowing 40 watts as the parasite commonly known as the "rat flea" This the output of our generator, it is practicable to wind hypothesis has been confirmed as the result of several the machine so as to give 1 volt and 40 amperes, or experiments. When plague-infested and healthy rats 40 volts and 1 ampere, or anything between these figwere incarcerated separately in wire cages, thereby ures, always remembering that whatever voltage we preventing them coming into contact with one another, get, we must divide 40 by that number to find the the healthy rodents became infected, and it was also amperes. The machine we are about to consider is so ascertained that guinea pigs could also become contam- arranged as to deliver current at either of two voltinated in the same manner. But on the other hand, ages, according to adjustment; that is, if we wind for if the plague-stricken rats, immune, however, from the 8 volts 5 amperes, we can also obtain 16 volts $2 \frac{1}{2}$ am. if the plague-stricken rats, immune, however, from the 8 volts 5 amperes, we can also obtain 16 volts $21 / 2$ am-
flea, were confined and permitted to come into free peres if we'wish, by merely changing two connections. flea, were confined and permitted to come into free peres if we'wish, by merely changing two connections.
physical contact with healthy animals, no such signs of infection were observed. Directly the fleas were introduced, the animals in a short time were all similarly affected, the progress of the epidemic varying in direct proportion to the number of fleas present. These tests conclusively proved that the parasite was the active agent in propagating the disease, since every precaution was adopted to prevent the possibility of infection being spread atmospherically. Moreover, similar tests were repeated in plague-infected houses. For instance, guinea pigs were permitted to run freely in a house, which though it had been disinfected still harbored parasites, with the result that the animals were found to be soon attacked by the fleas and con tracted plague, and the parasites caught on their bodies were found to be capable of spreading the epidemic. When, however, under the same conditions, the guinea pigs were immured in cages of wire gauze, thereby preventing the infesting of fleas; no ill results attended the animals. There is one important theory advanced in the preface to this report-that the plague advanced in the preface to this report-that
itself may in reality be a disease of fleas.

\section{Light Paint for Machinery.}

There is a very marked tendency at the present time on the part of manufacturers of machinery to make a departure from the use of black or dark paint in finishing their product. It has been the custom for a long time to cover the heavier parts of machinery of all kinds with paint or enamel of somber hue and the only variation which seemed permissible was an occasional striping of gilt or some bright color. During recent years a revolution has been going on in the matter of the construction and design of workshops and with it has come the demand for machinery painted some bright color. Not infrequently there is a demand for white, while light gray, buff, and cream color are favorites. The recommendation for this change is that the machine shop presents a much more attractive appearance and that the light surfaces of the machinery are responsible for the reflection of a great deal of light while the black absorbs the rays. The power plants of some of the new office buildings, hotels, and theaters are now regarded as show features of the establishment and one up-town hotel in New York has special accommo"ations for visitors. The engine room is in a very accessible place and it is fitted with a gallery for the convenience of spectators. Hardly a night passes but that a theater party with men and women in evening dress is to be seen viewing the installation with interest. This plant is finished in white with stripings of gold. The New York, New Haven and Hartford Railroad Company, in ordering ma. chinery for the new power plant at Readville, Mass., reserved the right to name the color of the Mass., reserved the right to name the
paint to be applied to the machinery.

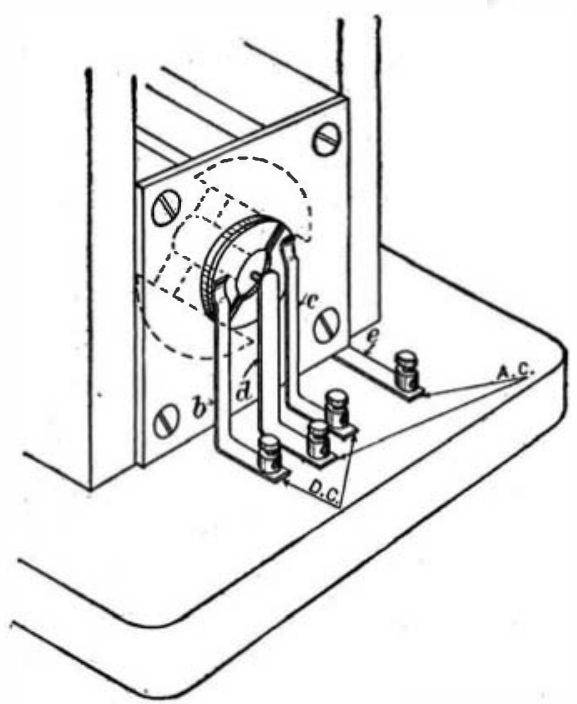

Fig. 3.-The Commutator.

at both voltages. At any store handling electrical goods, a telephone magneto generator, either new or second-hand, may be bought for a small sum. The kind known as "bridging generator" should be selected; but before buying, the magnets should be tested as to strength, especially in a second-hand machine, as they will lose some of their magnetism if roughly handled. Another test is the shock. In most of these machines the current is collected by a spring resting on a pin in the end of the armature shaft. By placing a finger and thumb, one on this spring, the other on the metal body of the machine, considerable current should be

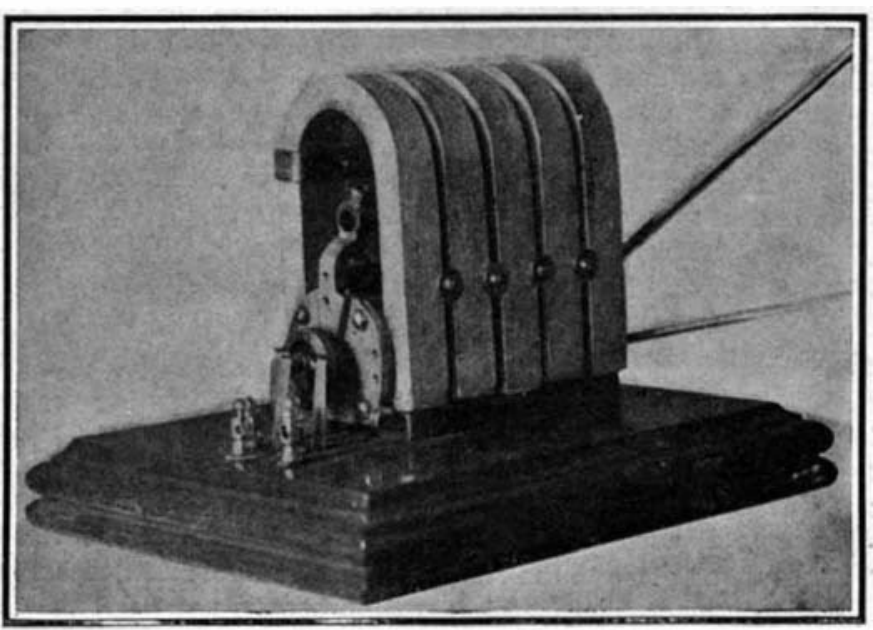

Fig. 4.-A SIMPLE EXPERIMENTAL DYNAMO. sulated; it is usually covered with paper or cloth shellacked on. Leave two or three inches free at the end of the wire, and see that the covering on the wire is not torn or loose. Wind the channel at one side of the shaft full first, and in going over to start the other side leave a loop of several inches of wire, as in Fig. 2; then fill the other side. Always wind tightly and get as much on as possible. There is almost always a groove cut around the armature used for binding the bundle of wire. Wrap a turn of wire tightly in this groove, and solder it, or at least, twist it as tight as possible, or when the machine is running at a high speed, centrifugal force will throw the wires out against the pole pieces, spoiling the winding.

When the loop left in the center of the coil is cut there are practically two separate coils on the armature. If the starting end of the whole winding is connected to the shaft or body of the armature, and the finishing end to the pin by soldering, while the remain ing ends are connected together, the higher voltage will result. For the low voltage the coils are separated, and both starting ends connected to the shaft, with both finishing ends to the pin. The machine may now be put together again, that is, the armature and bearings assembled with the pole pieces, and the shaft given a whirl to see that it runs all right. Now, drive the communtator onto the pin at the end of the shaft. The metal pieces are insulated from each other by a 1-16-inch or less air gap; but one must be connected to the shaft, the other to the pin in the end. Probably this can best be done with a bit of No. 23 copper wire and a speck of solder. Be very careful to remove every trace of soldering fluid after the operation. The slot in the commutator should be parallel with the iron of the armature, as shown in Fig. 3. A little cement will make it solid in this position, but should not be used until the machine is tested, as described later.

It is now time to make a base of some kind for the machine. This is, of course, a matter for individual choice, but do not make it too light; about one inch thick, of hard wood, and say 3 inches larger each way than the extreme dimensions of the machine, ought to be satisfactory. Drill and counterbore from the bottom of the base for screws to hold the machine; you will find tapped holes already in the bottom of the pole pieces; screw the machine down solid, and we are ready for the final operation-the fitting of the collector springs, or brushes. Spring brass 3-16 inch wide and $1-32$ inch thick is about right. Four pieces, made according to Fig. 3, are fastened to the base by binding posts in the locations shown; $b$ and $c$ rest against the commutator, not too heavily (these serve to collect direct current); $\iota$ against the flattened end of the pin in the center, and $e$, which is simply a straight strip clamped under the machine, and making good connection with it, collect alternating current. These brushes should not press hard enough to interfere with the smooth and easy running of the armature.

In testing, have an assistant turn the handle while you connect the direct-current posts to some piece of apparatus-a small lamp, for instance. The commutator slot is now at right angles with the armature winding; but it may be found that a slight variation one way or the other from this position will increase the output. When the correct point has been found, the commutator may be connected to the shaft. In 